\title{
PENGGUNAAN APLIKASI QUIZIZZ SEBAGAI ALAT EVALUASI PEMBELAJARAN DALAM HUKUM NEWTON TENTANG GERAK
}

\author{
Munjaidah, Jimmy Lolowang, Farly Tumimomor \\ Fakultas Matematika dan Ilmu Pengetahuan Alam, Universitas Negeri Manado \\ email: mujahidakis@gmail.com
}

\begin{abstract}
ABSTRAK
Untuk menuju pendidikan yang lebih baik diperlukan pemanfaatan teknologi informasi dan komunikasi untuk membantu dalam proses pembelajaran dan alat evaluasi yang berkualitas. Aplikasi Quizizz adalah salah satu alat evaluasi pembelajaran berbasis online yang dapat digunakan oleh guru dan peserta didik. Telah dilakukan penelitian yang terkait dengan materi hukum newton tentang gerak menggunakan alat evaluasi pembelajaran aplikasi Quizizz. Tujuan penelitian ini adalah untuk mengetahui apakah alat evaluasi Quizizz efektif dalam membantu meningkatkan hasil belajar siswa pada materi Hukum newton tentang gerak. Penelitian ini dilakukan pada siswa kelas X di SMA Negeri 1 Tondano dengan 21 responden untuk penggunaan aplikasi Quizizz sebagai alat evaluasi pembelajaran. Desain penelitian ini menggunakan One Group Pretest-Posttest Design dan instrumen yang digunakan berupa pretest dan posttest menggunakan alat evaluasi pembelajaran aplikasi Quizizz. Penelitian ini dimulai dari pretest, pelaksanaan pembelajaran fisika dengan Zoom Meeting dan diakhiri dengan posttest. Hasil penelitian ini diperoleh skor rata-rata nilai pretest sebesar 29.90 dan nilai posttest sebesar 85.10. Dari hasil penelitian uji N-Gain diperoleh nilai sebesar 79,0985 dilihat dari pengkategorian tafsiran efektivitas dengan presentase $>76 \%$. Jadi dapat dikatakan bahwa pembelajaran materi hukum newton tentang gerak menggunakan alat evaluasi pembelajaran Quizizz termasuk dalam kategori efektif.
\end{abstract}

Kata kunci : Quizizz, Alat Pembelajaran, Hukum Newton tentang Gerak

\section{ABSTRACT}

For better education it is necessary to use information and communication technologies to support the learning process and tools for quality assessment. The Quizizz application is an online based learning assessment tool that can be used by teachers and students. Newton's law of motion was examined using the Quizizz application learning assessment tool. The purpose of this study was to determine whether the Quizizz evaluation tool was effective in improving students' learning outcomes using Newton's law of motion. This study was carried out on class X students of the SMA Negeri 1 Tondano with 21 respondents who use the Quizizz application as a learning assessment tool. The design of this study used the One Group Pretest-Posttest design and the tools used were Pretest and Posttest using the Quizizz application learning assessment tool. This research begins with the pretest, the implementation of the physics learning with Zoom Meeting and ends with the post-test. The results of this study gave an average score of 29.90 pretest and posttest scores of 85.10. The results of the $\mathrm{N}$-Gain test give a value of 79.0985, as can be seen from the categorization of the effectiveness interpretation with a percentage $>76 \%$. So it can be said that learning Newton's law of motion with the Quizizz learning assessment tool falls into the effective category.

Keywords : Quizizz, learning tools, Newton's laws of motion 


\section{PENDAHULUAN}

Pendidikan merupakan salah satu faktor yang sangat penting bagi manusia dalam perkembangan ilmu pengetahuan dan teknologi seperti yang semakin berkembang. Pendidikan juga merupakan suatu hal yang penting untuk meningkatkan kualitas dan kemampuan seseorang, peran dari pendidikan sendiri yaitu untuk menumbuhkan dan mengembangkan potensi yang telah ada dalam diri manusia melalui kegiatan belajar mengajar (Kurnia Dewi, 2018) .

Untuk menuju pendidikan yang baik dan maju maka diperlukan adanya peningkatan proses pembelajaran dan evaluasi pembelajaran yang berkualitas, dalam tingkat keberhasilan tidak hanya sebuah proses pendidikan dapat dilihat juga dari hasil evaluasi pembelajarannya. Didalam mewujudkan alat evaluasi pembelajaran yang berkualitas tentunya tidak lepas dari pengaruh penerapan teknologi dan ilmu pengetahuan. Dengan diterapkannya ilmu pengetahuan dan teknologi di dalam dunia pendidikan diharapkan bisa membuat perubahan yang lebih baik dalam berbagai aspek kehidupan manusia (Mardupi, 2012).

Evaluasi pembelajaran merupakan sejumlah teknik yang tidak boleh dilewatkan dan harus diterapkan oleh tenaga pendidik dalam pelaksaan aktifitas pembelajaran. Evaluasi pembelajaran adalah sebuah kegiatan yang terus menurus dilakukan dalam rangkaian tahapan proses belajar mengajar yang baik, kegiatan evaluasi pembelajaran harus dilakukan secara terencana dan saling berhubungan antar faktor penunjang pendidikan, agar dapat berfungsi sebgai alat untuk mengetahui sejauh mana keefektifan pelaksanaan belajar mengajar yang telah dilakukan guna mencapai tujuan yang telah disusun oleh guru didalam rencana proses pembelajaran (RPP) (Erman, 2003).

\section{KAJIAN LITERATUR}

Alat evaluasi pembelajaran merupakan sesuatu yang bisa membantu dan mempermudah pekerjaan guru dalam mencapai tujuan pembelajaran yang lebih praktis dan efisien (Suharsimi, 2013). Didalam kegiatan evaluasi pembelajaran, fungsi alat digunakan untuk memperoleh lebih baik, sesuai dengan perencanaan pembelajaran ketika akan melakukan evaluasi. Pada proses pembelajaran tentunya ada model pembelajaran yang digunakan oleh guru salah satu model pembelajaran yang digunakan dalam kegiatan penelitian ini yaitu ekspositori. (Saam, 2007) Strategi Ekspositori adalah strategi pembelajaran yang menekankan kepada proses penyampaian materi secara verbal dari seorang guru kepada sekelompok siswa dengan maksud agar siswa dapat menguasai materi pelajaran sesuai dengan tujuan yang telah ditentukan. Dalam model pembelajaran ekspositori guru harus memberikan penjelasan atau menerangkan kepada siswa dengan cara berceramah. Quizizz adalah aplikasi berbasis daring yang dapat dibuka melalui browser web. Melalui aplikasi Quizizz, guru dapat menggabungkan instruksi, review dan evaluasi. Quizizz merupakan aplikasi dapat digunakan untuk membuat kuis interaktif multiplayer yang dapat diakses melalui perangkat computer, smartphone atau tablet untuk menyelesaikan sebuah kuis (Amornchewin). Quizizz juga memungkinkan siswa untuk saling bersaing dalam memotivasi mereka belajar sehingga hasil belajar bisa meningkat. Game Quizizz dapat membantu motivasi belajar siswa dan meningkatkan hasil belajar. Hal ini sejalan dengan pendapat Dewi, C. K. (2018 : 43) yang mengatakan bahwa pembelajaran berbasis permainan mempunyai potensi yang baik untuk dijadikan sebagai media pembelajaran yang efektif karena dapat merangsang komponen visual dan verbal (Setiawan, Wigati, \& Sulistyaningsih, 2019 ). Hasil belajar secara umum dapat didefinisikan sebagai penilaian dari siswa (Young, Klemz \& Murphy 2003) dan perubahan yang dapat diamati, dibuktikan dan terukur dalam kemampuan atau presentasi yang dialami oleh siswa sebagai hasil dari pengalaman belajar (Nameth \& Long, 2012). Hasil belajar juga dapat dikatakan sebagai polapola perbuatam, nilai-nilai, pengertianpengertian, sikap-sikap, apresiasi dan keterampilan. Jika suatu benda diam, untuk memulainya bergerak memerlukan gaya, yaitu gaya yang diperlukan untuk mempercepat suatu benda dari kecepatan nol ke kecepatan bukan nol dan untuk sebuah benda yang sudah bergerak, jika ingin mengubahnya baik searah maupun besarnya membutuhkan gaya. Aristoteles (384-322 SM) percaya bahwa gaya diperlukana untuk membuat benda bergerak sepanjang bidang horizontal. Bagi Aristoteles, 
keadaan alami suatu benda sedang diam, dan kekuatan diyakini diperlukan untuk membuat benda tetap bergerak. Lebih lanjut Aristoteles mengemukakan, semakin besar gaya pada benda tersebut, semakin besar pula kecepatannya. jika tidak ada gaya yang diterapkan pada benda bergerak, benda itu akan terus bergerak dengan kecepatan konstan dalam satu langkah cepat. Sebuah objek memperlambat hanya jika banyak dikeluarkan padanya. Galileo dengan demikian menafsirkan gesekan sebagai gaya yang mirip dengan tarikan dan tarikan biasa.

\section{METODE PENELITIAN}

\section{Tempat dan Waktu Penelitian}

Penelitian ini dilakukan pada siswa kelas X pada akhir tahun ajaran 2020/2021 di SMA Negeri 1 Tondano.

\section{Populasi dan Sampel}

1) Populasi

Populasi dalam penelitian ini adalah siswa kelas X akhir tahun ajaran 2020/2021 SMA Negeri 1 Tondano.

2) Sampel

Sampel dalam penelitian ini adalah siswa kelas $\mathrm{X}$ yang berjumlah 21 siswa di SMA Negeri 1 Tondano.

\section{Jenis dan Desain Penelitian}

Berdasarkan judul penelitian dan permasalahan diatas penelitian ini menggunakan motode kuantitatif. Penelitian ini merupakan penelitian eksperimen. Pada penelitian ini disusun desain penelitian yang menggunakan One Group Pre-test Post-test Design, dalam penelitian diberikan terlebih dahulu pretest kemudian diberikan perlakuan atau treatmen lalu diberikann posttst dengan alat evaluasi pembelajaran berbasis online aplikasi Quizizz.

Desain penelitian dapat dilihat pada gambar berikut :

\section{$\mathrm{O}_{1} \longrightarrow \mathrm{X} \longrightarrow \mathrm{O}_{2}$ \\ Gambar 1. One Group Pretest-Postest Design}

\section{Variabel Penelitian}

Dalam penelitian ini terdapat 2 jenis variabel yaitu :

1. Variabel bebas dalam penelitian ini yaitu diberikan perlakuan atau treatmen pada Hukum Newton tentang Gerak dengan melalui sebuah pretest kepada siswa per individu.

2. Variabel terikat dalam penelitian ini yaitu hasil belajar siswa pada materi Hukum

Newton tentang Gerak yang di ukur dengan menggunakan alat evaluasi pembelajaran berbasis online aplikasi Quizizz.

\section{Instrumen Penelitian}

Instrument yang digunakan dalam penelitian ini yaitu dalam bentuk tes, tes yang diberikan kepada siswa soal prestest dan soal posttest yang berbentuk pilihan ganda dengan alat evaluasi aplikasi Quizizz.

\section{Teknik Pengumpulan Data}

Tahap pelaksanaan penelitian ini dimulai dengan pretest menggunakan aplikasi Quizizz untuk mengetahui kemampuan awal siswa. setelah itu melaksanakan pembelajaran daring. Kemudian pelaksanaan postets menggunakan aplikasi Quizizz. Kegiatan selanjutnya hasil dari pretest dan posttest di analisis lalu membuat kesimpulan berdasarkan hasil yang diperoleh.

\section{Teknik Analisis Data}

Untuk mengetahui hasil belajar siswa dengan menggunakan alat evaluasi aplikasi Quizizz data yang diperoleh berupa data pretest dan posttest dianalisis menggunakan statistic uji-t menggunakan rumus paired samples t-test dan uji n-gain, namun sebelum melakukan uji-t dan uji n-gain dilakukan uji persyaratan diantaranya uji normalitas dan uji homogenitas.

\section{HASIL DAN PEMBAHASAN Hasil Penelitian}

Berdasarkan hasil penelitian ini dengan menggunakan aplikasi Quizizz sebagai alat evaluasi, penelitian ini merupakan penelitian eksperimen dengan menggunakan sampel sebanyak 21 peserta didik kelas X IPA 1 di SMA Negeri 1 Tondano. Dari hasil analisis diperoleh data rata-rata penelitian ini dengan menggunakan model pembelajaran ekspositori dengan alat evaluasi pembelajaran berbasis online aplikasi Quizizz dapat dilihat pada tabel 2 berikut:

Tabel 1. Data Hasil Peningkatan

\begin{tabular}{|c|c|c|c|c|}
\hline \multirow[b]{2}{*}{$\begin{array}{c}\text { No } \\
\text {. }\end{array}$} & \multirow[b]{2}{*}{$\begin{array}{l}\text { Responde } \\
\mathrm{n}\end{array}$} & \multicolumn{2}{|c|}{ Hasil Penelitian } & \multirow{2}{*}{$\begin{array}{c}\text { Peningkata } \\
n\end{array}$} \\
\hline & & $\begin{array}{c}\text { Pretes } \\
\mathrm{t}\end{array}$ & $\begin{array}{c}\text { Posttes } \\
\mathrm{t}\end{array}$ & \\
\hline 1. & AK & $13 \%$ & $66 \%$ & $53 \%$ \\
\hline 2. & AW & $20 \%$ & $100 \%$ & 80 \\
\hline 3. & A & $29 \%$ & $100 \%$ & $71 \%$ \\
\hline
\end{tabular}




\begin{tabular}{clccc}
\hline 4. & CP & $20 \%$ & $53 \%$ & $33 \%$ \\
\hline 5. & CM & $46 \%$ & $93 \%$ & $47 \%$ \\
\hline 6. & DS & $46 \%$ & $66 \%$ & $20 \%$ \\
\hline 7. & EM & $13 \%$ & $80 \%$ & $67 \%$ \\
\hline 8. & ET & $20 \%$ & $73 \%$ & $53 \%$ \\
\hline 9. & FM & $60 \%$ & $93 \%$ & $33 \%$ \\
\hline 10. & IM & $26 \%$ & $93 \%$ & $67 \%$ \\
\hline 11. & JR & $26 \%$ & $86 \%$ & $60 \%$ \\
\hline 12. & JP & $6 \%$ & $93 \%$ & $87 \%$ \\
\hline 13. & JT & $73 \%$ & $100 \%$ & $27 \%$ \\
\hline 14. & JA & $53 \%$ & $86 \%$ & $33 \%$ \\
\hline 15. & JM & $26 \%$ & $100 \%$ & $74 \%$ \\
\hline 16. & KR & $26 \%$ & $66 \%$ & $40 \%$ \\
\hline 17. & KK & $13 \%$ & $66 \%$ & $53 \%$ \\
\hline 18. & ML & $33 \%$ & $100 \%$ & $67 \%$ \\
\hline 19. & SW & $40 \%$ & $100 \%$ & $60 \%$ \\
\hline 20. & S & $33 \%$ & $73 \%$ & $40 \%$ \\
\hline 21. & ZP & $6 \%$ & $100 \%$ & $94 \%$ \\
\hline & & & & \\
\hline
\end{tabular}

dapat meningkatkan hasil belajar siswa, dan dari hasil analis pengambilan data dan pembahasan maka dari penelitian ini beberapa hal dapat disimpulkan diantaranya :

1. Alat evaluasi pembelajaran aplikasi Quizizz dapat meningkatkan hasil belajar siswa yang dapat dilihat tabel output Pired Sampel Test (uji t) -55,190 dimana hasil Mean menunjukkan nilai negative yang artinya terdapat peningkatan antara hasil pretest posttest.

2. Alat evaluasi pembelajaran aplikasi Quizizz terkait dengan materi hukum newton tentang gerak telah berjalan dengan baik dan dapat dikategorikan efektif digunakan dalam pembelajaran pada kondisi pandemi covid-19 seperti ini. Hal ini dilihat dari tabel output hasil uji N-gain dimana Mean yaitu 79,0985 dalam hal ini dilihat dari tabel kategori tafsiran efektivitas gain dimana termasuk dalam katategori efektif yakni kategori efektif terletak dipresentase $>76 \%$.

Dari beberapa kesimpulan diatas penelitian ini mempunyai keterbatasan yakni diantaranya yaitu :

1) Dari pihak sekolah mempunyai kebijakan mengenai waktu pembelajaran yang dimana pembelajaran daring yang dilakakukan memiliki waktu yang lebih singkat.

2) Penggunaan atau proses pembelajaran daring (online) seperti pada saat ini membutuhkan jaringan internet yang maksimum untuk agar pembelajaran terlaksanakan dengan baik.

\section{REFERENSI}

Amornchewin, R. (n.d). The Development of AQL Language Skil in Data Fefinition and Data Manipulatif Language Using Exercises with Quizizz for Students Learning Engagement. Indonesia Journal of Informatics Education., 2(2), 85-90.

Erika Marla, R. (n.d). Model Alat Evaluasi Keterampilan Membaca pada Buku Sekolah Eletronika Bhasa Indonesia Kelas X. Jurnal Pendidikan Bahasa dan Sasra Indonesia, 2.

Erman. (2003). Evaluasi Pembelajaran Matematika. Bandung: Universitas Pendidikan Bandung.

Giancoli, D. C (2005). Physics Prinsciples With Applications. In Person Education. 
Istambul, M. R., \& Supriadi, H. (2018). Evaluation of Blended Learning Implementation which is Conditioned to Optimize the Mastery of Student Knowledge and Skills. Internasional Journal of Engineering \& Technology, 7, 195-200.

Kunia Dewi, C. (2018). Pengembangan ALat Evaluasi Menggunakan Aplikasi Kahoot Pada Pembelajaran Matematika Kelas. Skripsi tidak diterbitkan. Lampung : Universitas Islam Negeri Raden Intan Lampung.

Mardupi, D (2012). Pengakuan, Penilaian dan Evaluasi Pendidikan. 56.

Saam, E. A. (2007). Constuctivist or expository instructional approaches: Does instruction. Journal of the Scholarship of Teaching and Learning, 22-31.

Setiawan, A., Wigati, S., \& Sulistyaningsih, D. (2019). Implementasi Media Game Edukasi Quizizz Untuk Meningkatkan Hasil belajar Matematika Materi Sistem Variabel Linear Tiga Variabel Kelas X IPA 7 SMA Negeri 15 Semarang Tahun Pelajaran 2019/2020. Seminar Nasional Edusainstek.

Setuju, S., Setiadi, B, R., Ratnawati, D., Widowati, A., Wijayanti, A., Johan, A, B., et al. (2018). Development E-Learning to Improve Student Activity with Technological Pedagogical and Content Kniwledge. Internasional Journal of Engineering \& Tecnology, 100-103

Sugiono. (2016). Metode Kuntitatif, Kualitatif dan R\&D. Bandung : Alfabeta.

Suharsimi, A. (2013). Dasar-Dasar Evaluasi Pendidikan Edisi Kedua Jakarta : Bumi Aksara.

Suryansyah, G. (2019). Penerapan Media Pembelajaran Berbasis Internet Dalam Meningkatkan Hasil Belajar Siswa V di Madrasah Ibtidaiyah Nurut Hidayah Kota Jambi.

PHYSICS EDUCATION, 4, 121-128.

Zhao, F. (2019). Using Quizizz to Integrate Fun Multiplayer Activity in the Accounting Classroom. Internasional Journal of Higher Education, 8. 